\title{
Editor's Notes
}

The attention of our readers is called to the appearance of the first number of the Revue Internationale d'Histoire de la Banque (International Review of the History of Banking). Contributions and inquiries should be directed to the editor, D. Demarco, via dei Tribunali, 213, Naples, Italy.

The American Institute of Aeronautics and Astronautics has recently authorized a $\$ 500$ prize contest for a book-length historical manuscript dealing with the science, technology, and/or impact of aeronautics and astronautics on society. Manuscripts and inquiries should be addressed to Professor I. B. Holley, Jr., Department of History, Duke University, Durham, N.C. 27706.

The Merrimack Valley Textile Museum has recently completed a compilation of its manuscript collections; copies may be obtained on request from Helena E. Wright, Keeper of Prints and Manuscripts, Merrimack Valley Textile Museum, North Andover, Massachusetts 01845. 


\section{Council on Research in Economic History}

The Council on Research in Economic History has established supplementary fellowships of $\$ 1200$ to be awarded to postdoctoral scholars who have already received fellowships from other sources but whose financial resources are still inadequate for their proposed research projects.

The Council continues to invite applications for modest grants to initiate or advance significant research in economic history.

Applications should be directed to Alfred D. Chandler, Jr., Department of History, The Johns Hopkins University, Baltimore, Maryland 21218.

The deadline for applications for both types of grants is April 15, 1969. 